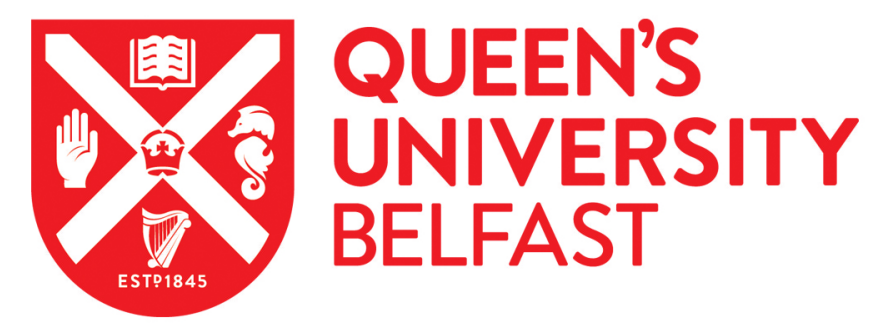

\title{
Beyond Good and Evil: Exploring the Mediating Role of Mental Toughness on the Dark Triad of Personality Traits.
}

Papageorgiou, K. A., Wong, B., \& Clough, P. (2017). Beyond Good and Evil: Exploring the Mediating Role of Mental Toughness on the Dark Triad of Personality Traits. Personality and Individual Differences, 119, 19-23. https://doi.org/10.1016/j.paid.2017.06.031

Published in:

Personality and Individual Differences

Document Version:

Peer reviewed version

Queen's University Belfast - Research Portal:

Link to publication record in Queen's University Belfast Research Portal

Publisher rights

Copyright 2017 Elsevier.

This manuscript is distributed under a Creative Commons Attribution-NonCommercial-NoDerivs License

(https://creativecommons.org/licenses/by-nc-nd/4.0/), which permits distribution and reproduction for non-commercial purposes, provided the author and source are cited

\section{General rights}

Copyright for the publications made accessible via the Queen's University Belfast Research Portal is retained by the author(s) and / or other copyright owners and it is a condition of accessing these publications that users recognise and abide by the legal requirements associated with these rights.

Take down policy

The Research Portal is Queen's institutional repository that provides access to Queen's research output. Every effort has been made to ensure that content in the Research Portal does not infringe any person's rights, or applicable UK laws. If you discover content in the Research Portal that you believe breaches copyright or violates any law, please contact openaccess@qub.ac.uk. 
MENTAL TOUGHNESS AND THE DARK TRIAD OF PERSONALITY

Beyond Good and Evil: Exploring the Mediating Role of Mental Toughness on the Dark Triad of Personality Traits 


\begin{abstract}
The Dark Triad (DT) involves three closely related personality traits: narcissism, psychopathy and Machiavellianism. Mental toughness (MT) is a multi-facet trait that entails positive psychological resources, which are important across a range of achievement contexts. Research that examined the association between MT and the DT returned mixed findings. The present study aimed at: (1) exploring the association between MT and the DT using a considerable larger sample in comparison to previous studies; (2) investigating whether MT mediates the association between narcissism with psychopathy and Machiavellianism. The mediation model revealed that narcissism exerts significant negative indirect effects on both psychopathy and Machiavellianism, through MT. The implications of these findings for reducing socially undesirable outcomes, often linked to the DT, are discussed.

Keywords: the dark triad of personality, narcissism, psychopathy, Machiavellianism, mental toughness, mediation model
\end{abstract}




\subsection{Introduction}

Mental Toughness (MT) is an umbrella term that entails positive psychological resources, which are important across a range of achievement contexts (Clough, Earle, \& Sewell, 2002). The Dark Triad of personality (DT) includes the traits of subclinical narcissism, subclinical psychopathy and Machiavellianism (Paulhus \& Williams, 2002). The current study tested directly the relationship between all four traits in a large adult sample; and a statistical model, which suggests that subclinical narcissism will exert negative-rather than positive_effects on both subclinical psychopathy and Machiavellianism, when MT is included in the model as a mediator.

\subsection{Mental Toughness}

A number of traits have been identified that buffer against the negative impacts of stressful situations. These include grit (Duckworth, Peterson, Matthews, \& Kelly, 2007), buoyancy (A. J. Martin \& Marsh, 2008), resilience and hardiness. Research on resilience primarily explores factors and processes that have a protective function on individuals experiencing adversity (Luthar, Sawyer, \& Brown, 2006; Masten, 2004). Similarly, research has explored hardiness (Kobasa, 1979) in relation to performance, leadership, conduct, and health (Godlewski \& Kline, 2012). Individuals scoring high on hardiness typically appraise stressful situations positively and employ adaptive coping behaviours (Funk, 1992). Mental Toughness (MT) is a personality trait that allows integrating many aspects of the previous coping literature.

MT reflects an effective coping mechanism as reaction to stressors and it allows individuals to proactively seek out opportunities for personal growth (St Clair-Thompson et al., 2015). While MT shares some conceptual similarities with hardiness, it clearly differs in its 
additional emphasis on confidence in one's abilities and interpersonal relations. Individuals who score high on MT are not only able to remain committed when confronting with stress, they are also confident about successfully completing the task and are assertive in social situations. MT is also distinct from grit, described by Duckworth, Peterson, Matthews and Kelly (2007) as perseverance and passion for long-term goals. While individuals, who score high on grit, may work strenuously toward goals despite self-doubt, mentally tough individuals believe that they are truly worthwhile people and maintain the self-confidence to achieve goals. Furthermore, they are able to control their emotion effectively in the face of setbacks and challenges.

Clough et al. (2002) conceptualised MT as a global construct that can manifest in any area of life, including personal relationships, vocational endeavours, and sport. Their 4C's model is the most frequently used conceptualization of MT. Clough et al., (2002) characterised MT as a composite of four interrelated but independent components: (1) control (life and emotion): the tendency to feel and act as if one is influential and keep anxieties in check; (2) commitment: the tendency to be deeply involved in pursuing goals despite difficulties that arise; (3) challenge: the tendency to see potential threats as opportunities for self-development and to continue to strive in changing environments; and (4) confidence (in abilities and interpersonal): the belief that one is a truly worthwhile person in spite of setbacks, and the ability to push oneself forward in social settings.

\subsection{The Dark Triad of Personality}

The Dark Triad (DT) is a personality cluster, defined at the subclinical level, and composed of three distinct, but overlapping personality traits: narcissism, psychopathy and Machiavellianism (Paulhus \&Williams, 2002). The construct of subclinical or "normal” 
narcissism includes facets retained from the clinical syndrome namely, grandiosity, entitlement, dominance, and superiority (Paulhus \& Williams, 2002). The adaptation of psychopathy to the subclinical sphere is recent (Lilienfeld \& Andrews, 1996). Subclinical psychopathy is characterised by high impulsivity and thrill seeking along with low empathy and anxiety (Paulhus \& Williams, 2002). Machiavellianism is synonymous with manipulation; individuals scoring high on Machiavellianism employ self-serving strategies, they are master manipulators and deceivers, who care little for moral and societal norms (Kapoor, 2015).

The DT traits are conventionally perceived as socially malevolent; however, they have also been associated with success in the workforce, in short-term relationships and in various socially desirable outcomes (e.g., Jonason et al., 2009, 2010; Young \& Pinksy, 2006; Onley et al., 2013). For example, a study reported that individuals who scored high on Machiavellianism were socially central, peers liked them, they were socially skilled, and well adjusted (Hawley, 2003). Other studies have found that narcissism was associated with higher self-rated creativity (Furnham, Hughes \& Marshall, 2013) and emotional intelligence (Petrides et al., 2011). Finally, a recent study reported that traits related to psychopathy (such as boldness) and narcissism predicted creative achievement, and better divergent thinking scores (Galang et al., 2016). These findings suggest that the DT involve three complex personality traits that have both socially desirable and toxic elements.

Furnham, Richards and Paulhus, (2013) suggested that - although the DT traits sometimes show the same outcome correlates and they exhibit moderate-sized positive intercorrelations - lumping them together implies a simplistic distinction between good and bad personalities. Using mediation models could be useful for investigating, the degree to which 
associations between the DT traits are influenced by the presence of other traits.

\subsection{The Dark Triad and Mental Toughness}

Studies that explored the association between MT and the DT returned mainly mixed findings. The most recent study on this area reported positive associations between all components of MT and narcissism, psychopathy and Machiavellianism (Sabouri et al., 2015). However, a previous study reported negative correlations between MT and psychopathy and Machiavellianism; and a positive correlation between MT and narcissism (Onley, Vaselka, Schermer \& Vernon, 2013). Onley et al. (2013) suggested that narcissism might be qualitatively unique among the DT traits because, in the same sample, it correlated positively with a prosocial and adaptive trait (MT) as well as with psychopathy and Machiavellianism. Vaselka et al., (2012) explored the DT traits and the five factor model of personality and reached a similar

conclusion: "With regard to the development of our understanding of the Dark Triad variables, it is evident from these findings that while Machiavellianism and psychopathy exhibited a pattern of correlations that is to be expected with measures of social malevolence, narcissism did not follow suit.” (p. 421).

\subsection{The Current Study}

We tested directly the association between MT and its four components (4Cs) with narcissism, psychopathy and Machiavellianism in a considerably larger sample in comparison to previous research in this area. Using mediation analysis, we investigated whether associations between the DT traits are influenced by the presence of a prosocial trait, namely MT. Considering previous findings that showed that narcissism correlates positively with MT; and that it might be a unique trait among the DT traits; we tested a statistical model, which suggests 
that the relationship between narcissism with psychopathy and Machiavellianism is mediated by individuals’ level of MT.

Specifically, we hypothesised that: (1) narcissism will correlate positively with MT as well as with psychopathy and Machiavellianism; (2) narcissism would exert a significant negative indirect effect on psychopathy and Machiavellianism through mental toughness. In this model, narcissism increases MT, which decreases levels of psychopathy and Machiavellianism.

\subsection{Method}

\subsection{Sample}

Participants $(N=608)$ were recruited online through advertisements on social networks (e.g. Facebook) as well as through word of mouth. Participants' mean age was 24.31 years $(S D=$ 9.16, range 18-79); $56.9 \%$ of the participants were females. Participants received detailed information regarding the aims of the study and the voluntary basis of their participation and they signed informed consent forms. The participants did not receive compensation for taking part in the study.

\subsection{Measures}

2.2.1 Mental Toughness. The Mental Toughness Questionnaire 48 (MTQ48) is the most frequently used measure of MT as conceptualized by Clough et al. (2002). It has an average completion time of 10 minutes and responses to its 48 items are given on a 5-point Likert scale anchored at 1 = strongly disagree and 5 = strongly agree. Twenty-two items are reverse coded; An overall MT score can be calculated by summing up individual items of the questionnaire. Example items include "I can usually adapt myself to challenges that come my way" and "I don’t usually give up under pressure". The MTQ48 has generally shown good reliability (Crust \& Swann, 2011; Perry, Clough, Crust, Earle, \& Nicholls, 2013). Previous studies have verified the 
instrument's construct and criterion validity, and the MTQ48 has received independent support for its factor structure through confirmatory factor analyses (Horsburgh et al., 2009). In the present study, an overall Cronbach's alpha of .88 was obtained.

2.2.2 The Dark Triad. The Short Dark Triad questionnaire (SD3; Jones and Paulhus, 2014) assesses the Dark Triad of personalities, narcissism, psychopathy and Machavellianism, as conceptualized by Paulhus and Williams (2002). The SD3 has 27 items, 9 for each scale, and responses are given on a 5-point Likert scale, with $1=$ strongly disagree and $5=$ strongly agree . Example items include: "I like to use clever manipulation to get my way" (Machiavellianism), "People see me as a natural leader" (narcissism) and "It's true that I can be mean to others" (psychopathy). The score for each subscale represents the average score of their 9 corresponding items. Studies by Jones and Paulhus (2014) have demonstrated that the SD3 has high reliability and validity, including construct validity, as well as external validity with informant ratings. In the present study the Cronbach's alpha for narcissism, psychopathy and Machiavellianism was $.69, .72$ and .79 , respectively.

\subsection{Procedure}

All questionnaires were combined to form a single document and they were made available online via SurveyMonkey (www.surveymonkey.com). Each participant received a message containing a link to the online questionnaire and password access as well as a unique participant code. After they agreed to take part in the study, participants were asked for demographic variables (age, gender, level of education, language, nationality and religion) and contact details. Questionnaire completion was self-paced, and participants could proceed to the subsequent page only once they had answered all items. Upon completion of the study the participants were given an online written debrief. 


\subsection{Statistical Analyses}

2.4.1 Descriptive Statistics. Demographics and questionnaire data were examined using Descriptive Statistics in SPSS Version 22. Kurtosis and skewness, were calculated to test for normality in the distribution (skewness $<1.0$ ). The scores of the remaining variables were approximately normally distributed (see Table 1 for details). Levene’s test was used to examine the assumption of equality of variances between males and females for the MTQ and each scale of the Dark Triad. Analysis of variance was used to explore sex differences in MTQ and the SD3.

2.4.2 Covariates. Previous research (e.g. Marcant et al., 2009) has shown that demographic variables, such as age, can influence MT. Prior to exploring the relationships between MT and DT traits, we investigated the potential effects of age, gender and education on the MT and DT traits. The results are reported in section S1 of the supplementary material. Based on the findings of this additional analysis, age was used as a covariate in all subsequent analysis. Gender was used as a covariate in all analysis that involved psychopathy as a dependent variable.

2.4.3 Correlations and Mediation Analysis. Partial correlations were carried out in SPSS to test for significant association between MT and the DT (at $p<.05$ as each hypothesis was tested separately). Bias-corrected bootstrap 95\% confidence intervals (CI) were calculated using a sample size of 5000. Hierarchical regression analyses of total effect, direct effect, and biascorrected bootstrap 95\% confidence intervals (CI) of the indirect effect (we used 5000 bootstrap resamples as suggested by Preacher \& Hayes (2008)) using the PROCESS macro for SPSS (Hayes, 2012) were used. CI that do not contain zero indicate significant mediation effects (Hayes, 2013). 


\subsection{Results}

\subsection{Descriptive Statistics}

Descriptive statistics for total MT and the DT are presented in Table 1. Descriptive statistics for the four components of the MT are presented in Table S1 in the supplementary material. The mean overall MT score of our sample falls within the fifth Sten (Stens divide the score scale into ten units. Each unit has a bandwidth of half a standard deviation except the highest unit, Sten 10, which extends from 2 standard deviations above the mean; and the lowest unit, Sten 1, which extends from 2 standard deviations below the mean), when compared to general population norms, suggesting that the sample is representative.

Table 1 should be placed here

\subsection{Correlations between Mental Toughness, Narcissism, Psychopathy, and}

\section{Machiavellianism}

Partial correlations between MT, narcissism, psychopathy, and Machiavellianism are presented in Table 2. Table S2 in the supplementary material presents the correlations between the 4Cs of MT and the DT traits. As hypothesised, narcissism correlated positively with MT ( $r$ $=.20, p<.001,95 \%$ CI $[0.113,0.284])$, psychopathy $(r=.31, p<.001,95 \%$ CI [0.225, 0.385]) and Machiavellianism ( $r=.16, p=.001,95 \%$ CI $[0.068,0.253])$. MT correlated negatively with psychopathy ( $r=-.08, p=.045,95 \%$ CI [-0.161, -0.003]). MT showed a marginally significant negative correlation with Machiavellianism ( $r=-.07, p=.069,95 \%$ CI [-0.155, 0.010]). Psychopathy was correlated positively with Machiavellianism $(r=.40, p<.001,95 \%$ CI [0.332, 0.471]). 
Table 2 should be placed here

\subsection{Mediation effects of Mental Toughness on the relationships between the Dark Triad}

In line with our hypotheses, narcissism exerted a significant negative indirect effect on psychopathy through mental toughness, 95\% CI [-0.054, -0.011]. The biased-corrected bootstrapping confidence interval for the indirect effect did not contain zero. After controlling for mental toughness, there was a significant positive direct effect of narcissism on psychopathy, $b=0.331, S E=0.04, p<.001$. The results are illustrated in Figure 1 .

Figure 1 should be placed here

Narcissism also had a significant negative indirect effect on Machiavellianism through mental toughness, 95\% CI [-0.055, -0.005]. After controlling for mental toughness, the direct effect of mental toughness on Machiavellianism was positive, $b=0.210, S E=0.048, p<.001$. The results are illustrated in Figure 2.

Figure 2 should be placed here

\subsection{Discussion}

The current study explored the association between the dark triad of personality traits and MT in a large adult sample. We tested the association between MT with narcissism, psychopathy and Machiavellianism both directly (correlation analysis); and in a statistical model, where the relationship between narcissism with psychopathy and Machiavellianism was mediated by MT.

Our findings contradict, in part, previous research that reported positive associations 
between MT and its 4Cs with all the DT traits (see Sabouri et al., 2015). The correlation between narcissism and MT was positive and stronger than the correlations reported for MT and psychopathy and MT and Machiavellianism. The results of the present study are in line with previous findings reported by Onley et al. (2013), who suggested that narcissism might be unique among the DT traits in that, it encapsulates to a larger extent (in comparison to psychopathy and Machiavellianism), prosocial and adaptive behaviours (see also Vaselka et al., 2012). In order to explore this hypothesis further, we tested the correlations between the 4Cs of MT and the DT traits. This analysis also revealed positive correlations between the MT components of challenge, control and confidence with narcissism; and negative correlations between commitment, control and psychopathy; and commitment and Machiavellianism. Similarly to Onley et al., (2013) the strongest correlation was between confidence and narcissism ( $r=.21$ in Onley et al., (2013); $r=$ .26 in our study). The fact that confidence is the strongest correlate (out of all the 4Cs of MT) of narcissism seems to support Petrides et al., (2011) suggestion that, the exaggerated sense of selfworth and pride associated with narcissism can render a narcissist optimistic, motivated, assertive, and successful in relationships.

Another explanation for these findings could be that, scores for narcissism obtained using the SD3 might be biased towards assessing narcissism as a prosocial trait, linked to healthy selfesteem, rather than assessing the antisocial aspects of narcissism. Similar criticism has been applied to other measures (see for example, Brown et al., 2009) employed to assess subclinical narcissism, such as the Narcissistic Personality Inventory (NPI; Raskin \& Hall, 1979). Maples, Lamkin and Miller (2014) suggested that the SD3 narcissism scale measures primarily the grandiose aspects of this construct; while other short measures of this trait, such as the Dirty Dozen (Jonason \& Webster, 2010) capture both vulnerable and grandiose features of narcissism 
(Maples et al., 2014). Similarly, it could be argued that the SD3 measure tends to focus on the maladaptive, rather than prosocial, aspects of psychopathy and Machiavellianism. This is a possibility that needs to be explored in the future.

The results of the mediation analysis suggest that MT can be a suppressor variable in the relationship between narcissism with psychopathy and Machiavellianism. A suppressor variable is a variable, which increases the predictive validity of another variable (or set of variables) by its inclusion in a regression equation (MacKinnon, Krull \& Lockwood, 2000). Within a mediation model, a suppression effect would be present when the direct and mediated effects of an independent variable on a dependent variable have opposite signs (MacKinnon et al., 2000; Tzelgov \& Henik, 1991). The findings hint to the idea that individuals, who score high on narcissism and MT can appraise stressful situations positively, employ adaptive coping behaviours (instead of trying to manipulate others, a behaviour typically associated with Machiavellianism) and remain focus on their goals (instead of changing goals to seek immediate reward, a behaviour typically associated with psychopathy). The joint manifestation of high narcissism and high MT may facilitate success across achievement contexts.

\subsection{Limitations and Directions for Future Studies}

We acknowledge a number of limitations in the present study design. Despite advantages of online data collection, such as low use of economic resources and reaching large and diverse samples (Gosling \& Mason, 2015), there is less control over questionnaire completion, which might affect responses. As we exclusively used self-reported data, there is a possibility that the responses were influenced by social desirability, particularly in the context of the assessment of 
antisocial traits, and common-method variance (Podsakoff, MacKenzie, Lee, \& Podsakoff, 2003). Experts' rating and data collection from multiple raters would enhance the validity of the results.

Due to the cross-sectional design of our study, we could not determine whether narcissism increases MT or whether MT increases subclinical levels of narcissism. Future research should address these issues by employing longitudinal designs. In addition, although some of the reported associations were statistically highly significant, the effect sizes were small, which poses difficulties in terms of making inferences about the practical value of some of the findings. The intercorrelation between narcissism and Machiavellianism in this study was smaller than the correlations reported in previous studies (see for example, Maples et al., 2014 and Jones \& Paulhus, 2014). This could be due to differences between the sample in the present study and the samples in the previous studies. For example, both Maples et al. (2014) and Jones and Paulhus (2014) recruited their samples from Amazon's Mechanical Turk (MTurk) and their participants were adults from the USA. The majority of participants in the current study were from the UK and they were recruited online through advertisements on social networks (e.g. Facebook) as well as through word of mouth. As such, differences in the recruitment process and cultural differences could have influenced the way that participants completed the SD3 scales; this is a hypothesis that future studies should explore.

\subsection{Conclusion}

The findings of the current study support the view that personality traits are complexbeyond good and evil—involving both positive and negative aspects. Exploring narcissism in relation to MT can be particularly helpful, when trying to identify and promote the adaptive tendencies of this "seemingly dark" trait of personality. Onley et al., (2013) reported that the 
correlation between narcissism and MT is primarily due to common non-shared environmental factors. This suggests that non-shared environmental effects play a role in the extent to which these traits are exhibited together (Onley et al., 2013). Furthermore, it has been suggested that MT develops partially through positive youth experiences (Gould, Griffes, \& Carson, 2011). These may include a particular motivational climate (e.g., enjoyment, challenge, and mastery experiences), external assets such as having social support networks, and certain developmental experiences (e.g., critical incidents, competitive rivalry, vicarious experiences, and demonstration of ability; Connaughton, Hanton, \& Jones, 2010; Connaughton, Wadey, Hanton, \& Jones, 2008). For example, Jones and Parker (2013) showed that positive youth experiences, and especially initiative experiences, of young athletes were associated with higher MT (SMTQ), and may therefore be worth promoting (M. I. Jones \& Parker, 2013).

Taking together, these findings suggest that training MT could facilitate the development of the adaptive-rather than maladaptive-aspects of narcissism. Studying the joint manifestation of narcissism with MT, and in relation to other personality traits, can have implications for eliminating the negative impact and increasing the positive effects, that people exhibiting higher levels of these behaviours have on themselves and on the society. 


\section{References}

Ames, D. R., Rose, P., \& Anderson, C. P. (2006). The NPI-16 as a short measure of narcissism. Journal of Research in Personality, 40(4), 440-450.

Brown, R. P., Budzek, K., \& Tamborski, M. (2009). On themeaning and measure of narcissism. Personality and Social Psychology Bulletin, 35, 951-964.

Christie, R., \&Geis, F. (1970). Scale construction. Studies in machiavellianism, 10-34.

Clough, P., Earle, K., \& Sewell, D. (2002). Mental toughness: The concept and its measurement. In I. M. Cockerill (Ed.), Solutions in sport psychology (pp. 32-43). Boston, MA: Cengage Learning.

Connaughton, D., Hanton, S., \& Jones, G. (2010). The development and maintenance of mental toughness in the world's best performers. The Sport Psychologist, 24(2), 168-193.

Connaughton, D., Wadey, R., Hanton, S., \& Jones, G. (2008). The development and maintenance of mental toughness: Perceptions of elite performers. Journal of Sports Sciences, 26(1), 83-95.

Duckworth, A. L., Peterson, C., Matthews, M. D., \& Kelly, D. R. (2007). Grit: perseverance and passion for long-term goals. Journal of personality and social psychology, 92(6), 1087.

Egan, V. (2012). Positively Unpleasant: Personality, the Dark Triad, Happiness and Subjective Well-Being. Talk presented at the meeting of the European Association for Personality Psychology, Trieste, Italy.

Funk, S. C. (1992). Hardiness: a review of theory and research. Health Psychology, 11(5), 335.

Furnham, A., Richards, S. C., \& Paulhus, D. L. (2013). The Dark Triad of personality: A 10 year review. Social and Personality Psychology Compass, 7(3), 199-216. 
Furnham, A., Hughes, D. J., \& Marshall, E. (2013). Creativity, OCD, narcissism and the Big Five. Thinking Skills and Creativity, 10, 91-98.

Galang, A.J.R., Castelo, V.L.C., Santos III, L.C., Perlas, C.M.C., and Angeles, M.A. (2016). Investigating the prosocial psychopath model of the creative personality: Evidence from traits and psychophysiology. Personality and Individual Differences, 100, 28-36

Godlewski, R., \& Kline, T. (2012). A model of voluntary turnover in male Canadian Forces recruits. Military Psychology, 24(3), 251.

Gosling, S. D., \& Mason, W. (2015). Internet research in psychology. Annual Review of Psychology, 66, 877-902.

Gould, D., Griffes, K., \& Carson, S. (2011). 9 Mental toughness as a life skill. Mental toughness in sport: Developments in theory and research, 163.

Gucciardi, D. F., Hanton, S., \&Mallett, C. J. (2012). Progressing measurement in mental toughness: A case example of the Mental Toughness Questionnaire 48. Sport, Exercise, and Performance Psychology, 1(3), 194.

Hawley, P. H. (2003). Prosocial and coercive configurations of resource control in early adolescence: A case for the well-adapted Machiavellian. Merrill-Palmer Quarterly (1982-), 279-309.

Jonason, P. K., \& Webster, G. D. (2010). The Dirty Dozen: A concise measure of the dark tdad. Psychological Assessment, 22, 420-432.doi:10.1037/a0019265

Jonason, P. K., \& Kavanagh, P. (2010). The dark side of love:Love styles and the Dark Triad. Personality and Individual Differences, 49, 606-610.

Jonason, P. K., Li, N. P., Webster, G. D., \& Schmitt, D. P.(2009). The Dark Triad: Facilitating a short-term mating strategy in men. European Journal of Personality, 23, 5-18. 
Jones, D. N., \&Paulhus, D. L. (2014). Introducing the Short Dark Triad (SD3) A Brief Measure of Dark Personality Traits. Assessment, 21(1), 28-41.

Jones, M. I., \& Parker, J. K. (2013). What is the size of the relationship between global mental toughness and youth experiences? Personality and Individual Differences, 54(4), 519523.

Kapoor, H. (2015). The creative side of the dark triad. Creativity Research Journal, 27(1), 58-67.

Kobasa, S. C. (1979). Stressful life events, personality, and health: an inquiry into hardiness. Journal of personality and social psychology, 37(1), 1.

Lee, K., Ashton, M. C., Wiltshire, J., Bourdage, J. S., Visser, B. A., \&Gallucci, A. (2013). Sex, power, and money: Prediction from the Dark Triad and Honesty-Humility. European Journal of Personality, 27(2), 169-184.

Lilienfeld, S. O., \& Andrews, B. P. (1996). Development and preliminary validation of a self report measure of psychopathic personality traits in noncriminal populations. Journal of Personality Assessment, 66, 488-524.

Luthar, S. S., Sawyer, J. A., \& Brown, P. J. (2006). Conceptual issues in studies of resilience. Annals of the New York Academy of Sciences, 1094(1), 105-115.

MacKinnon, D. P., Krull, J. L., \& Lockwood, C. M. (2000). Equivalence of the Mediation, Confounding and Suppression Effect. Prevention Science: The Official Journal of the Society for Prevention Research, 1(4), 173.

Maples, J. L., Lamkin, J., \& Miller, J. D. (2014). A test of two brief measures of the dark triad: The dirty dozen and short dark triad. Psychological assessment, 26(1), 326. 
Marchant, D. C., Polman, R. C. J., Clough, P., Jackson, J. G., Levy, A. R., \& Nicholls, A. R. (2009). Mental toughness: Managerial and age differences. Journal of Managerial Psychology, 24(5), 428-437.

Martin, A. J., \& Marsh, H. W. (2008). Academic buoyancy: Towards an understanding of students' everyday academic resilience. Journal of School Psychology, 46(1), 53-83.

Masten, A. S. (2004). Regulatory processes, risk, and resilience in adolescent development. Annals of the New York Academy of Sciences, 1021(1), 310-319.

Raskin, R., \& Hall, C. S. (1979). A Narcissistic personality inventory. Psychological Reports, 45, 590 .

Onley, M., Veselka, L., Schermer, J. A., \& Vernon, P. A. (2013). Survival of the Scheming: A Genetically Informed Link Between the Dark Triad and Mental Toughness. Twin Research and Human Genetics, 16(06), 1087-1095.

Paulhus, D. L., \& Williams, K. M. (2002). The dark triad of personality: Narcissism, Machiavellianism, and psychopathy. Journal of research in personality, 36(6), 556-563.

Petrides, K. V., Vernon, P. A., Schermer, J. A., \& Veselka, L. (2011). Trait emotional intelligence and the dark triad traits of personality. Twin Research and Human Genetics, 14(01), 35-41.

Podsakoff, P. M., MacKenzie, S. B., Lee, J.-Y., \& Podsakoff, N. P. (2003). Common method biases in behavioral research: a critical review of the literature and recommended remedies. Journal of Applied Psychology, 88(5), 879-903.

Sabouri, S., Gerber, M., Bahmani, D. S., Lemola, S., Clough, P. J., Kalak, N., ... \& Brand, S. (2016). examining Dark Triad traits in relation to mental toughness and physical activity in young adults. Neuropsychiatric disease and treatment, 12, 229. 
St Clair-Thompson, H., Bugler, M., Robinson, J., Clough, P., McGeown, S. P., \& Perry, J. (2014). Mental toughness in education: exploring relationships with attainment, attendance, behaviour and peer relationships. Educational Psychology(ahead-of-print), 122.

Tzelgov, J., Henik, A. (1991). Suppression situations in psychological research: Definitions, implications, and applications. Psychological Bulletin, 109, 524-536.

Veselka, L., Schermer, J. A., \& Vernon, P. A. (2012). The Dark Triad and an expanded framework of personality. Personality and Individual Differences, 53, 417-425.

Williams, K. M., Paulhus, D. L., \& Hare, R. D. (2007). Capturing the four-factor structure of psychopathy in college students via self-report. Journal of personality assessment, 88(2), 205-219.

Young, S. M., \& Pinksy, D. (2006). Narcissism and celebrity. Journal of Personality Research, 40, 463-471. 
Table 1. Descriptive Statistics for total Mental Toughness and the Dark Triad of personality traits

\begin{tabular}{lccccccc}
\hline Variable & Mean & Variance & Median & Range & Kurtosis & Skewness & Cronbach's $\alpha$ \\
\hline Mental Toughness & $3.43(0.38)$ & 0.15 & 3.44 & 2.50 & 0.39 & -0.18 & .88 \\
Narcissism & $2.92(0.57)$ & 0.33 & 2.89 & 3.56 & -0.16 & 0.03 & .69 \\
Psychopathy & $2.14(0.59)$ & 0.34 & 2.11 & 3.11 & -0.34 & 0.37 & .72 \\
Machiavellianism & $3.05(0.68)$ & 0.46 & 3.06 & 3.67 & -0.13 & -0.08 & .79 \\
\hline
\end{tabular}

Table 2. Correlations between Mental Toughness, Narcissism, Psychopathy, and Machiavellianism

\begin{tabular}{|c|c|c|c|c|}
\hline Variable & Mental Toughness & Narcissism & Psychopathy & Machiavellianism \\
\hline Mental toughness & - & & & \\
\hline Narcissism & $.20 * * *$ & - & & \\
\hline Psychopathy & $-.08 * *$ & $.31 * * *$ & - & \\
\hline Machiavellianism & -.07 & $.16 * * *$ & $.40 * * *$ & - \\
\hline
\end{tabular}

Note: $N=608 ; * * p \leq .01 . * * * p \leq .001$ 
Figure 1. Multiple Mediator Model of Narcissism on Psychopathy through MT

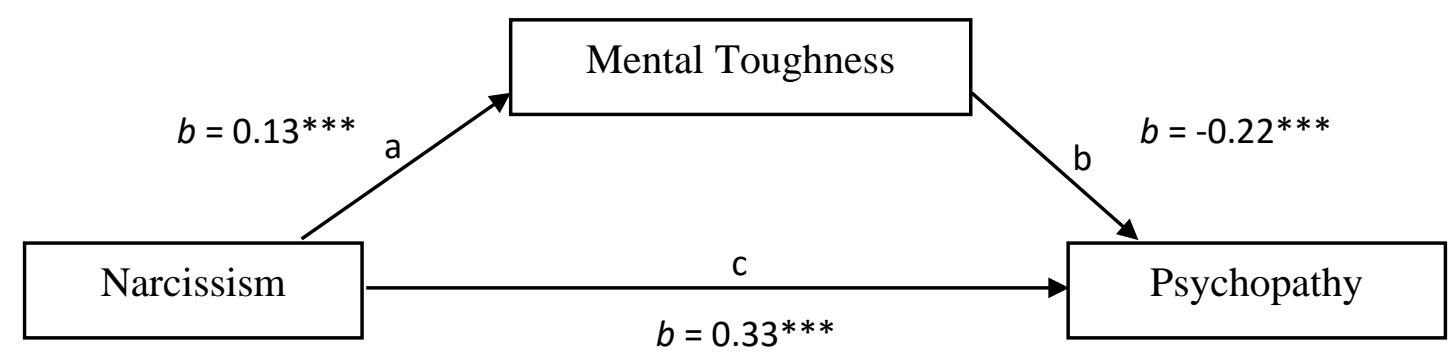

Figure 1. Multiple mediator model of the indirect effect of narcissism on Psychopathy. $b$ 's represent the unstandardised regression coefficients $\left({ }^{* * *} \mathrm{p}<.001\right)$. Total effect: $b=0.302$, $S E=0.040, p<.001$; (a) The effect of narcissism on mental toughness; (b) the effect of mental toughness on psychopathy after controlling for narcissism; (c) the direct effect of narcissism on psychopathy.

Figure 2. Multiple Mediator Model of Narcissism on Machiavellianism through MT

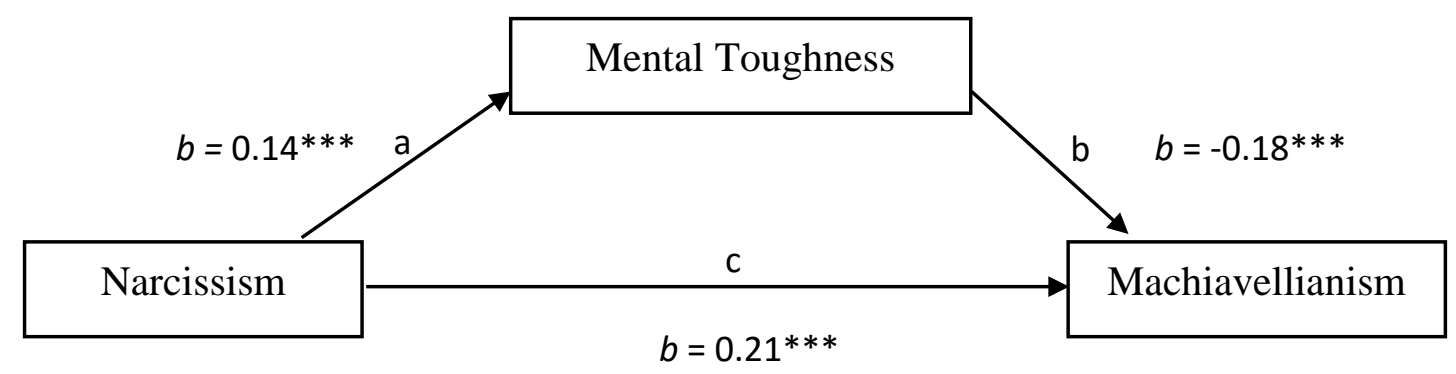

Figure 2. Multiple mediator model of the indirect effect of narcissism on Machiavellianism. $b$ 's represent the unstandardised regression coefficients $\left({ }^{*} \mathrm{p}<.05\right.$; ${ }^{* * *} \mathrm{p}<.001$ ). Total effect: $b=0.185, S E=0.048, p<.001$; (a) The effect of narcissism on mental toughness; (b) the effect of mental toughness on Machiavellianism after controlling for narcissism; (c) the direct effect of narcissism on Machiavellianism. 